\title{
Investigação de práticas anticompetitivas: um sistema de informação para apoio à interpretação de legislação por agências reguladoras
}

\author{
Alberto Pucci Junior \\ Professor de Sistemas de Informação na Faculdade de Ciências \\ Exatas e de Tecnologia da U niversidade Tuiuti do Paraná (UTP), \\ M.Sc. em sistemas de informação pela U niversidade de Londres e \\ doutor em meio ambiente e desenvolvimento pela U niversidade \\ Federal do Paraná. \\ E-mail: alberto.pucci@utp.br
}

\section{Resumo}

A inovação tecnológica, definida como a transformação de conhecimento em bens e serviços, gera produtos que são disponibilizados para a sociedade em uma economia capitalista altamente competitiva. Órgãos governamentais foram criados, no Brasil, com a intenção de estimular a inovação e evitar a concorrência desleal. A interpretação da conformação das práticas a leis e regulamentos existentes é a base de suas intervenções. Este trabalho apresenta uma proposta de ferramenta de apoio à interpretação jurídica. Um estudo de caso é utilizado para mostrar sua aplicação na análise de acordos de distribuição pelo comitê do governo britânico que investiga monopólios e fusões (Monopolies and Mergers Commission). $O$ principal objetivo é estimular o debate sobre a viabilidade de um sistema de computador para ajudar neste tipo de interpretação legal.

\section{Palavras-chave}

Sistemas de informação; Apoio à decisão; Legislação; Interpretação legal.

Research about anti-competitive practices: an information system for support to interpretation of legislation by regulating agencies

\begin{abstract}
Technological innovation, defined as the inception of services and goods from new knowledge, generates products, which are made available to society in a competitive capitalist economy. Government agencies were created to stimulate innovation and to prevent unfair competition. Their intervention is based on the application of laws and rules. This article presents a tool to help legal interpretation and a case study to illustrate its use in analysis of exclusive distribution agreements by the Monopolies and Merges Commission. The main purpose here is to initiate and stimulate debate around the feasibility of computer systems for legal interpretation.
\end{abstract}

Keywords

Information systems; Decision support; Laws; Legal interpretation

\section{IN TRO D U ÇÃ $O$}

A inovação tecnológica nas empresas depende de uma série de condições. Além do grande investimento interno em pesquisa, recursos e pessoas qualificadas, as organizações dependem de um ambiente favorável para que a inovação ocorra, ou seja, para que os resultados ultrapassem suas fronteiras e cheguem ao mercado. A transformação de conhecimento em bens e serviços gera produtos que serão disponibilizados para a sociedade em uma economia capital ista altamente competitiva. Leis e regulamentos governamentais procuram influenciar a existência de um mercado suficientemente competitivo para estimular a inovação e, ao mesmo tempo, evitar a concorrência desleal. Ó rgãos governamentais no Brasil foram criados com essa inten ção, bem como agências reguladoras foram encarregadas de avaliar o desempenho dos setores privatizados. A interven ção dessas instituições é baseada, eminentemente, na aplicação correta das leis e regulamentos. Assim, justifica-se a utilização de uma ferramenta para apoiar a decisão sobre práticas anticompetitivas. A interpretação da conformação dessas práticas às leis e regulamentos existentes contribui para a produção de um ambiente favorável à inovação, sem 0 qual muitas idéias, disponibilizadas na forma de bens e serviços, não poderiam colaborar para o progresso da sociedade e para a melhoria da qualidade de vida. U ma ferramenta de apoio à interpretação jurídica e um estudo de caso são utilizados aqui para mostrar sua aplicação na análise de acordos de distribuição, em relação à legislação européia, pelo comitê do governo britânico que investiga monopólios e fusões (M onopolies and $M$ ergers Commission).

\section{A INTERPRETAÇÃO DA LEGISLAÇÃO E A A PLICAÇÃO DE SISTEMAS ESPECIALISTAS}

As leis e regulamentos estabelecem as normas que governam o comportamento permitido em determinada situação. Os vários artigos, ou regras na legislação, orientam também a interpretação dos termos empregados. Ao determinar como uma lei deve ser 


\section{Alberto Pucci Junior}

aplicada, deve-se levar em consideração, além do sentido comum das palavras usadas, a intenção de seus autores, quando indicada conforme o caso. Também a investigação da conformidade das práticas em relação à legislação depende de consulta a uma grande quantidade de informação e ocorre de duas formas diferentes. Em primeiro lugar, aplica-se o processo dedutivo que avalia a aplicação das regras sobre os fatos, um processo puramente burocrático. Em seguida, avalia-se 0 significado das palavras nas regras. São feitas diferentes leituras, e, assim que o significado preciso é alcançado, verifica-se se as regras são aplicáveis no caso, um processo interpretativo. Os sistemas especialistas que se propõem a apoiar a tomada de decisão legal devem ser capazes de realizar ambos os processos. Segundo Stamper (1991), é um consenso entre os juristas que os sistemas especialistas baseados em regras deixam muito a desejar em relação a esse tipo de tomada de decisão, porque, apesar de atender adequada-mente ao processo burocrático, falham ao manusear problemas de interpretação. A limitação desses sistemas é, portanto, 0 manuseio dos significados, que são a raiz dos problemas de interpretação. A principal questão é fazer a ligação entre os textos do corpo das leis eos elementos do mundo real ao qual atribuem significados.

H enry (1990) investigou a viabilidade de se utilizar um sistema especialista para apoiar a decisão neste tipo de situação. 0 autor conclui que um sistema especialista é viável, se for projetado para operar em um modo de apoio à decisão, aumentando a capacidade do especialista humano, em vez de um sistema solucionador de problemas.

Porém, mesmo assim, sistemas especialistas não são apropriados para esta tarefa. 0 significado das regras de produção, que é a unidade básica de um sistema especialista, está cercado de incertezas, e estas regras são criadas sem nenhum critério objetivo, da mesma forma que os objetos na programação orientada a objetos e as entidades no modelo de entidaderelacionamento. Portanto, os sistemas especialistas baseados em regras são extremamente limitados para manusear normas sociais, mesmo quando estas estão formalizadas na legislação.

Em contrapartida, a análise semântica (Stamper et alii, 1988) é uma técnica para especificar 0 funcionamento de uma organização em termos de que ações e comportamentos são requeridos das pessoas que o compõem. U ma especificação pode ser obtida para atender a diferentes finalidades: entender a organização, descrever o que ela faz, desenvolver sistemas. A técnica lida diretamente com 0 problema fundamental das diferenças de significado e pode, portanto, como no caso apresentado, ser utilizada para apoiar o processo de interpretação. Basicamente, a análise semântica envolve a modelagem de todas as ações, comportamentos e agentes responsáveis que caracterizam determinada organização e os arranja em uma seqüência de dependências existentes.

\section{A TÉCNICA dA ANÁLISE SEMÂn TICA}

Essa técnica tem como pressuposto que todo ambiente social e físico suporta certas formas de ação ou comportamento. Os suportes (Gibson, 1977) são as primitivas do modelo semântico. Eles têm de ser ordenados de maneira a detalhar a dependência de um suporte sobre a preexistência de outros. Esta dependência ontológica é que dá origem ao nome da representação gráfica do esquema semântico resultante: 0 diagrama ontológico. 0 diagrama ontológico apresenta o conjunto de suportes possíveis em determinado domínio da realidade. U ma análise completa exige que descrevamos para cada suporte, em cada nó do quadro, as normas que determinam quando cada instância deste suporte é realizada. U ma especificação completa deve mostrar a infra-estrutura total de suportes e as normas que controlam quando estes são realizados, isto é, passam a existir. Um exemplo de diagrama ontológico é apresentado na figura 1.

FIGU RA 1

\section{D iagrama ontológico}

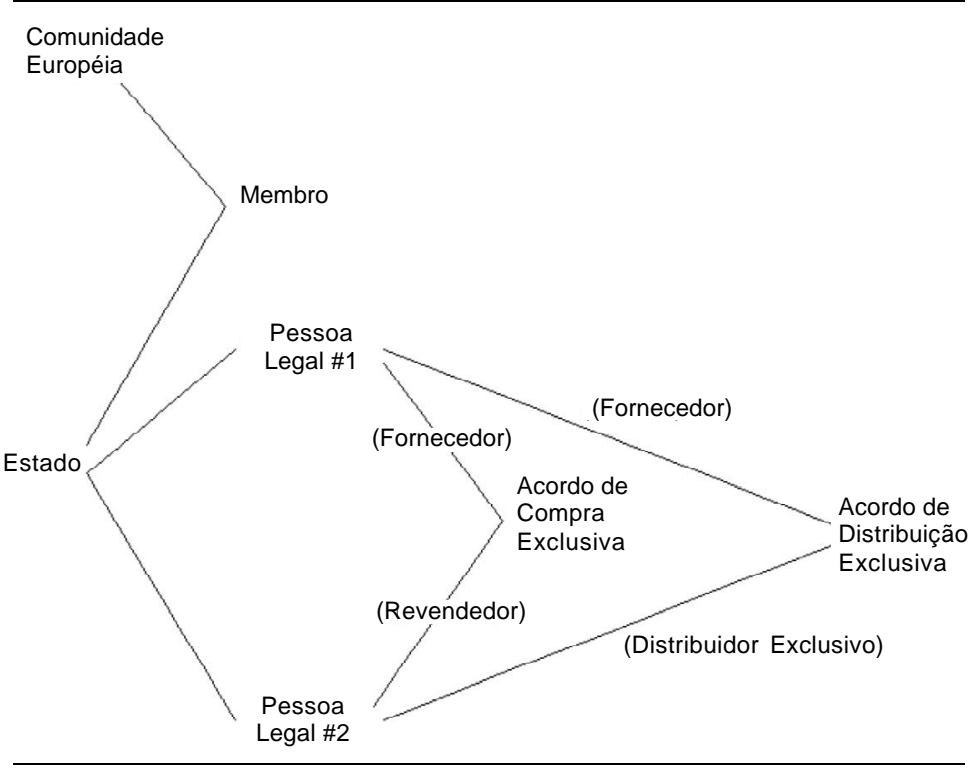

Fonte: Pucci, 1992 
Investigação de práticas anticompetitivas: um sistema de informação para apoio...

0 esquema semântico representado em um diagrama ontológico deve ser independente de detalhes sobre a estrutura do negócio ou procedimentais, isto é, como o negócio é executado. Especificando desta maneira as tarefas primordiais, as necessidades de informação da organização podem ser demonstradas sem comprometimento prévio com quaisquer modelos computacionais ou procedimentos de negócios existentes.

A análise semântica é uma técnica que permite aos analistas detalhar as conexões entre os sinais utilizados nas comunicações organizacionais e o comportamento para os quais estes se referem no mundo das ações. A própria análise envolve a aplicação de parâmetros semânticos que reconfiguram o conhecimento e 0 comportamento de um determinado problema sob investigação na forma requerida pelo formalismo.

0 formalismo, o modelo semântico, que é empregado nesta técnica, é originado de uma linguagem de especificação de sistemas chamada NORM A (NORM S and Affordances), desenvolvida no projeto LEGOL (LEG ally 0 riented Lan guage), iniciado na London School of Economics and Political Science em 1973 e atualmente em continuação na U niversidade de Twente na H olanda. V ersões da linguagem LEGOL foram implementadas em computadores. Cada versão foi testada em uma grande variedade de negócios e de problemas legais. 0 modelo semântico foi gradualmente sendo aperfeiçoado até culminar na linguagem de normas e suportes (N O RM A), que forma o ápice desta série de linguagens e pode ser utilizada para representação de normas legais, segundo seus autores, com vantagens sobre regras de produção e objetos (Stamper, 1989).

Por exemplo, um dos grandes problemas das tecnologias orientadas a objetos é a arbitrariedade com que estes são criados. $\mathrm{N}$ a programação orientada a objetos, qualquer coisa pode ser representada como um objeto, como no trabalho de $H$ ayes (1989), no qual a legislação foi implementada como um objeto e servia apenas para referência. Hayes comenta, em sua conclusão, a fal ta de critérios precisos para representar a realidade e para a interpretação da legislação. A programação orientada a objetos é uma ferramenta muito poderosa para 0 desenvolvimento de sistemas de computador, porém esta arbitrariedade e a falta de um método consistente de representação da realidade impedem a efetivação de seus benefícios.
LEG O L, a linguagem orientada para leis, entretanto, foi criada para representar normas sociais e padrões de comportamento em organizações com o máximo de precisão. A legislação foi o seu material experimental, e uma série de trabalhos comprovou sua aplicabilidade tanto para elaboração de leis (C rooks, 1981) quanto para sua interpretação (Stamper et alii, 1988). 0 modelo semântico supera a arbitrariedade mencionada anteriormente e provê uma plataforma para trabalhos mais profundos em significado e interpretação. 0 modelo resultante da análise semântica é implementado em uma forma que suporta a interpretação de textos, dentro do qual a validade da interpretação está previamente garantida.

\section{APRESENTAÇÃO DE UM ESTUDO DE CASO}

O Comitêde M onopólios eFusões ( $M$ onopolies and M erges Commission - M M C) é um órgão estatutário criado para investigar casos específicos relacionados com situações de monopólios, fusões, práticas anticompetitivas, 0 desempenho de órgãos do setor público e a regulamentação de certas indústrias privatizadas (M M C, 1990). O Comitê é independente do governo para conduzir suas investigações e para emitir suas conclusões. 0 Comitê é financiado pelo D epartamento de Indústria e Comércio do governo britânico.

0 Comitê não tem poderes para iniciar suas próprias investigações. As referências (fatos geradores de investigações) são feitas pelo secretário de Estado da Indústria e do Comércio, pelo diretor-geral do 0 ffice of Fair Trading, ou pelo órgão regulamentador no caso das indústrias privatizadas. Os principais tipos de referências são fusões, fusões jornalísticas, monopólios, práticas anticompetitivas, setor público, indústrias privatizadas (gás, aeroportos, telecomunicações, água e eletricidade) efunções sob o B roadcasting A ct de 1990.

0 atual título do Comitê e suas principais responsabilidades são derivados do Fair Trading Act de1973. 0 utras atividades estão definidas no Competition Act de 1980 e nos estatutos de privatização relevantes. U ma vez que uma referência é feita, o presidente do Comitê indica um grupo de membros que representem um conjunto de conhecimentos e experiências relevantes à investigação. 0 grupo é dirigido pelo próprio presidente, ou por um dos vice-presidentes, e apoiado por uma equipe administrativa. Para a maioria das referências, o grupo estará preocupado em buscar fatos que operam ou que venham a operar contra 0 interesse público como definido no Fair Trading A ct de 1973. 


\section{Alberto Pucci Junior}

Segundo Pucci Jr. (1992), em algumas investigações, o M M C necessita acatar a legislação Européia, como no caso de acordos entre fabricantes e representantes, os quais podem estar sujeitos ao A rtigo 85(1) do Tratado de Roma, que proíbe acordos que venham afetar o comércio en tre estados membros da Comunidade Européia e tenham como efeito prevenir, restringir ou distorcer a competição dentro da Comunidade.

Qualquer acordo entre empresas dentro deste mercado é julgado anticompetitivo, a não ser que acate certas condições. 0 Artigo 85(3) do Tratado de Roma prevê exceções para certos acordos, desde que estes estejam de acordo com as regulamentações 1983/ 83 e 1984/ 83 da Comissão Européia. Estas regulamentações governam acordos de distribuiçãa exclusiva e acordos de compra exclusiva, respectivamente. Em acordos de compra exclusiva, o representante concorda em não comprar os bens ou mercadorias em questão de outro que não seja 0 referido fornecedor. Nos acordos de distribuição exclusiva, o representante recebe um território onde 0 fornecedor não apontará ou fornecerá nenhum outro representante.

Além das regulamentações, a Comissão Européia publicou um material para orientar a interpretação destas na sua aplicação. 0 objetivo era de ajudar os contratantes a manter seus acordos legais e garantir a aplicação uniforme da lei. A Comissão enfatiza que, em adição ao significado ordinário das palavras utilizadas, deve-se levar em consideração a intenção dos regulamentos quando se determinar como aplicá-los. Este material ( $\mathrm{N}$ ota Interpretativa) tem também força de lei.

N este material, termos como revenda, bens e contratantes são definidos. Torna-se claro que somente a revenda de bens ou produtos é coberta pela legislação, e não 0 suprimento de serviços. 0 aluguel, ou leasing, dos bens ao consumidor pelo revendedor também está coberto.

Em resumo, o processo descrito anteriormente consiste em interpretar os contratos de distribuição e testá-los contra a interpretação da legislação. A interpretação deve ser formalizada de modo a manter o conhecimento dos especialistas do M M C e aplicar o mesmo teste, qualquer que seja a investigação. U ma vez formalizado, certas tarefas podem ser passadas para o computador para se tirar vantagem dos seus recursos, tais como velocidade, animação e arquivamento e recuperação de dados.

Este processo, executado manualmente, consome muito tempo e nem sempre produz os melhores resultados.
Os volumes envolvidos não permitem que o Comitê faça uma análise profunda dos acordos de distribuição. 0 MMC está freqüentemente sob pressão para reduzir os prazos das investigações. Além disso, o processo de interpretação normalmente não é a principal preocupação das investigações, porque o M M C lida com muitas outras matérias vitais para suas conclusões, as quais, porém, devem estar de acordo com a legislação européia. Entretanto, o uso de uma ferramenta computadorizada para acelerar este processo necessita de um esquema prévio, como o resultado da análise semântica, o qual permite explorar todas as potencialidades da ferramenta (Pucci Jr., 1992).

\section{APLICANDO A ANÁLISE SEMÂNTICA NO ESTUDO DE CASO}

0 analista constrói o esquema semântico baseado nos termos empregados pelos agentes envolvidos para expressar suas visões subjetivas do negócio.

N este estudo de caso, o negócio é relativo a acordos que possam afetar o comércio entre os países membros da Comunidade Européia e, portanto, prejudiquem, restrinjam ou distorçam a competição dentro do M ercado Comum. Os agentes envolvidos são principalmente a Comissão da Comunidade Européia, que expressa suas visões nos Regulamentos 1983/ 83 e 1984/ 83 e na N ota que orienta a interpretação destes regulamentos, o Comitê de Fusões e M onopólios (M M C) do Governo Britânico, que analisará os acordos e os validará contra a legislação, e os Contratantes, que explicarão os termos utilizados em seus acordos.

0 esquema semântico resultante, já mostrado na figura 1 , emerge da legislação e ref lete os regulamentos. Os termos usados e explicados são selecionados a partir destes. 0 s regulamentos têm em comum os acordos en tre contratantes chamados de fornecedor e distribuidor exclusivo pelo Regulamento 1983/83 e fornecedor e revendedor pelo Regulamento 1984/83. I sto confirma 0 tratamento especial dado aos papéis e a necessidade de procurar termos mais gerais para denominar os atores, sabendo-se que fornecedor, revendedor e distribuidor exclusivo são termos válidos somente para este relacionamento. Isto reforça a estabilidade da estrutura ontológica.

Pessoa Legal (física ou jurídica) é o termo usado para representar os contratantes, que terão como antecedentes os estados membros (países) que reconhecerão sua existência. 0 sinal (\#) representa individualização e 0 
sinal (@) a autoridade que governa o comportamento do suporte.

O utro fato em comum entre os acordos é a definição e as obrigações relativas ao bem contratual e suas características, tais como a quantidade mínima e os produtos da linha a serem comprados, a marca a ser utilizada, a forma de embalagem e apresentação. A promoção de vendas é também comum aos dois regulamentos, sendo um suporte complexo que não será detalhado no exemplo. A promoção de vendas inclui propaganda, manutenção da rede de lojas, 0 armazenamento das mercadorias, 0 atendimento e os funcionários especializados ou com treinamento técnico.

Em relação aos produtos envolvidos, a Nota Interpretativa explica que somente a revenda de bens é coberta pelos regulamentos, e não o suprimento de serviços. Em termos legais, quando compramos algo, 0 que acontece é a transferência de propriedade - nós compramos o direito de propriedade do bem ou patrimônio. Há normas ou regras que regulam este processo, tais como o tipo de moeda a ser utilizada e 0 val or determinado pela autoridade ou agente responsável. Por exemplo, no caso do preço final, segundo os regulamentos, este não pode ser determinado pelo fornecedor ao revendedor.

A principal diferença entre os regulamentos é o uso do território. No caso dos acordos de distribuição exclusiva (Regulamento 1983/83), o distribuidor exclusivo recebe um território onde deve concentrar seus esforços de revenda e onde 0 fornecedor não venderá para outros distribuidores ou consumidores. No caso dos acordos de compra exclusiva (Regulamento 1984/83), não existe um território exclusivo e 0 fornecedor poderá vender para 0 consumidor.

0 esquema semântico demonstra que, uma vez que se tenha definido um termo, podemos utilizá-lo nas próximas definições. Por exemplo, pode-se usar fornecedor no lugar de pessoa legal envolvida em acordo de compra com a obrigação de suprir a outra parte. Isto permite a mesma precisão e economia de expressão encontradas na língua falada, sem afetar a estabilidade da estrutura ontológica (Backhouse, 1990).

A estabilidade do esquema pode ser testada contra certas condições, tais como emendas aplicadas a referências feitas ao M M C. É comum, durante uma investigação, receberem-se alterações no pedido original. Isto tem 0 mesmo efeito de modificações de necessidades de informação dos usuários para a análise e projeto de sistemas, mas o modelo é flexível e estável o suficiente para acomodar as al terações. Por exemplo, uma referência feita para a investigação sobre o fornecimento de fotocopiadoras eletrostáticas foi anunciada em 12 de setembro de 1990 para ser concluída em 12 meses. Em 14 de fevereiro de 1991, a referência foi alterada para incluir também fotocopiadoras eletrostáticas digitais na investigação, sem nenhuma ampliação do prazo (M M C, 1991).

Q uando os regulamentos expirarem, a estabilidade dos modelos poderá ser testada novamente. 0 que provavel mente acontecerá será a modificação das normas que regulam a existência e o comportamen to dos suportes, en quanto a estrutura ontológica básica permanecerá. Estas normas são principalmente os regulamentos e a nota interpretativa da Comissão da Comunidade Européia.

Finalmente, com a aplicação da análise semântica, vantagens adicionais podem ser obtidas. Além da ferramenta computadorizada, a orientação interpretativa dos funcionários do MMC pode também ser disponibilizada em forma de texto, para manter 0 conhecimento especialista para os novos membros do MMC.

Quando faz a análise dos acordos, o usuário decide que cláusulas são relevantes ou não. Este trabalho ainda pode ser feito manualmente, mas agora, com o diagrama ontológico, de maneira mais incisiva, levando a uma profunda compreensão do domínio, sem deixar de lado nenhum detalhe. Durante este processo, os contratantes, alvos da investigação, podem ainda ser consultados para explicar os termos empregados em seus acordos e também têm 0 direito de discordar da posição do M MC.

\section{CONSIDERAÇÕES FINAIS}

0 propósito do enfoque semiótico, especialmente do processo de análise semântica, é descrever o sistema de informações como um sistema social, colocando a tecnologia no seu devido lugar. N ão se considera uma panacéia para todos os problemas ou o único método para ser aplicado em todas as situações. Porém, com sua fundação filosófica, pode ser considerado um grande avanço na análise e projeto de sistemas, concentrando seus esforços em entender o sistema informal e revelando as limitações do sistema formal. 
Comparada com as técnicas convencionais, tais como 0 modelo relacional, modelo de entidade e relacionamentos, diagramas de fluxo de dados e sistemas especialistas, a análise semântica aponta a arbitrariedade com a qual o conhecimento e 0 universo de discurso são geralmente modelados. Cultura, comportamento e interação humana não são mais os empecilhos da análise e projeto de sistemas deliberadamente ignorados, mas centrais para o sistema de informações.

0 estudo de caso mostra que uma ferramenta para a análise de acordos comerciais e verificação do cumprimento da legislação inglesa e européia é viável, desde que seja utilizada como apoio à decisão. O u seja, conforme recomenda Henry (1990), o sistema indica pontos suspeitos, mas a decisão final é do usuário.

Pode-se sugerir muitas aplicações similares. O nde quer que textos tenham de ser comparados para adequação a regras e regulamentos, este enfoque será útil. A coleta de orientação interpretativa é valiosa, sendo válido encarar este como um sistema para acumular a experiência de vários usuários e para documentar sua orientação interpretativa onde o domínio não é formal e baseado em regras. U ma vez que o diagrama ontológico tenha sido construído, o sistema poderá ser usado para documentar as regras prevalentes para fazer a descrição do sistema informal. Deste modo, a ferramenta poderá ser usada para construir uma especificação e para guiar os novos usuários. Alternativamente, capturando-se as diferentes normas legais de diferentes países para um dado problema, os diferentes enfoques legislativos podem ser comparados. Como no caso dos acordos de distribuição, se a estrutura on tológica básica é abrangente, então pode ser usada como plataforma para estudar as normas legais que a compõem.

Como foi mencionado na introdução, o conhecimento da legislação e a interpretação jurídica são vitais para criar um ambiente adequado ao desenvolvimento, principalmente o tecnológico. Isto envolve a localização e 0 tratamento adequado desse tipo de informação, que deve estar disponível aos usuários. 0 modelo resultante da análise semântica pode ser facilmente transformado em hipertexto, permitindo assim sua disponibilização na Internet. U m exemplo disso pode ser encontrado em Pucci Jr. (2001). É a legislação de recursos hídricos que cria os comitês de bacia e ao mesmo tempo exige que seja conhecida para ser aplicada de forma correta no gerenciamento de bacias hidrográficas por esses comitês, compostos por diferentes atores da sociedade e não apenas por técnicos.

\section{REFERÊN C I AS}

BACKHOU SE, James. The use of semantic analysis in the development of information systems. 1990. Tese. (D outorado) - School of Economics and Political Science, London, 1990

CRO OKS, R.M. LEGOL as an aid for the drafting of legislation. 1981. Dissertação. (M estrado) - School of Economics and Political Science, London, 1981.

GIBSON, J. J. The theory of affordances in R.E.Shaw and J.Bransford (Ed.). Perceiving, acting and knowing. Hillsdake : Lawrence Erlbaum, 1977.

H AYES, B.M . An objetc-oriented programming implementation of a taxation and benefit program. London : School of Economics and Political Science, 1989. (Discussion paper TIDI/128. Taxation, Incentives and Distribution of Income Programme).

HEN RY, C. An expert system for the monopolies and merges commission: a feasibility study. 1990. Dissertação. (M estrado) - School of Economics and Political Science, London, 1990.

M M C. Indirectelectrostatic photocopiers: a report on the supply by man ufacturers and importers of indirect electrostatic photocopiers in the U nited Kingdom. London : H M SO, 1991.

The role of the commission. London : H M SO, 1990.

PU CCI JU NIOR., Alberto. The use of semantic analysis in the specification of information systems: a case study. 1992. Dissertação. (M estrado) - LSE, London, 1992.

Sistemas de informação e gerenciamento de recursos hídricos na Região M etropolitana de C uritiba, Paraná: entrea norma prescrita ea conduta concreta. 2001. Tese. (Doutorado em Meio Ambiente e D esenvolvimento) - U FPR, Curitiba, 2001.

STAM PER, R.K. The Role of Semantics in Legal Expert Systems and Legal Reasoning. Ratio Juris. Vol. 4 № 2 July 1991.

Nationality Act - a LEGOL Case Study and Comparison with PROLOG. LEGOL/NORMA working paper L84. 1985.

; ALTHAUS, K.; BACKHOUSE, J. M ethod for eliciting, analyzing, and specifying user requirements. In: OLLE, T. W. A. A.; VERRIJN -STUART, L. Bhabuta. (Ed.). Computerized assistance during the information systems life cycle. [S. I.] : N orth Holland, 1989.

et al. From database to normbase. In: CSCW ' 90 CO N FEREN CE, 1990, Los Angeles, California. [S. I. : s. n.], 1990.

et al. Semantic normal form? In: JONES, K. P. (Ed.). M eaning: the frontier of informatics. London : Aslib, 1988. 